\title{
113. Flower Initiation of Holoparasite, Aeginetia indica L. under the Nonparasitic Condition of Sterile Culture
}

\author{
By Yoshio Tashima, Mieko Matsumoto, and Seiki Kuroki
}

Laboratory of Forestry, Department of Agriculture, Kagoshima University

(Comm. by Tetsu Sakamura, M. J. A., Sept. 12, 1974)

Aeginetia indica L., (Orobanchaceae) is a holoparasitic plant widely distributed in the tropical and the temperate region of east and south Asia. The entire plant lacks chlorophyll completely and grows only parasitically on the roots of monocotyledonous plants, especially on these of Cyperales and Graminales. ${ }^{3)}$ Seeds sown in May, on the roots of its host, Miscanthus sinensis Anderss (Gramineae) growing in a garden pot, germinate well. The plant body of this parasite connects with the roots of the host and attains $2-3 \mathrm{~mm}$ in length by July and flowers in September. ${ }^{4), 16)}$ It is annual, but sometimes it does not flower in the first year and takes two years to reach the flowering stage.

Recently several attempts to culture the holoparasites including Aeginetia, Orobanche ${ }^{12), 13)}$ and Striga ${ }^{7), 8)}$ under a nonparasitic condition on the artificial media, have been reported.

The present authors found that Aeginetia indica L. is able to initiate flower primordia saprophytically on sterile nutrient media in the total darkness. Seeds collected from a wild population growing in the Takakuma Experimental Forest of Kagoshima University, from September to October, were utilized for the experiments, within one year after the harvest.

The seeds were sterilized at first with a $10 \%$ Lubelon-solution (initial solution contained $\left.1.75 \% \quad\left(\mathrm{C}_{2} \mathrm{H}_{5} \mathrm{Hg}\right)_{2} \mathrm{HPO}_{4}\right)$ for 60 minutes and rinsed with sterile distilled water about five times. Then they were shaken in a $10 \%$ calcium hypochorite solution for 15 minutes. About 100 to 150 seeds were sown on the culture media in each test tube and kept in the darkness.

The basic culture medium used in the present experiment, contained the following constituents: $\mathrm{NH}_{4} \mathrm{NO}_{3} 57.5 \mathrm{mg}, \mathrm{MgSO}_{4} \cdot 7 \mathrm{H}_{2} \mathrm{O}$ $120.0 \mathrm{mg} \mathrm{Ca}\left(\mathrm{NO}_{3}\right)_{2} \cdot 4 \mathrm{H}_{2} \mathrm{O} 117.0 \mathrm{mg}, \mathrm{KH}_{2} \mathrm{PO}_{4} 38.3 \mathrm{mg}, \mathrm{KCl} 43.0 \mathrm{mg}$, $\mathrm{MnCl}_{2} \cdot 4 \mathrm{H}_{2} \mathrm{O} 0.4 \mathrm{mg}, \mathrm{H}_{3} \mathrm{BO}_{3} 0.6 \mathrm{mg}, \mathrm{ZnSO}_{4} \cdot 7 \mathrm{H}_{2} \mathrm{O} 0.05 \mathrm{mg}, \mathrm{H}_{2} \mathrm{MoO}_{4} \cdot \mathrm{H}_{2} \mathrm{O}$ $0.02 \mathrm{mg}, \mathrm{CuSO}_{4} \cdot 5 \mathrm{H}_{2} \mathrm{O} 0.05 \mathrm{mg}, \mathrm{FeC}_{6} \mathrm{H}_{5} \mathrm{O}_{7} 10 \mathrm{mg}$, sucrose 5-20 g, difco Bacto Agar $10 \mathrm{~g}$ and distilled water $1000 \mathrm{ml}$.

The transfer medium was prepared by an addition of watermelon juice within 15 volume percent to the basic medium. The test tubes 
of $18 \times 150 \mathrm{~mm}$, each containing $10 \mathrm{ml}$ of the medium, were plugged with cotton wool and autoclaved under $1 \mathrm{~kg} / \mathrm{cm}^{2}$ over pressure for 20 minutes and slanted. After autoclaving, $\mathrm{PH}$ of the basic medium was 5.3-5.5.

Seed germination. Seeds of Aeginetia germinate easily on our basic medium as well as on other media (White's, ${ }^{17)}$ Spoerl's, ${ }^{10}$ ) B. K. $P{ }^{6}{ }^{6}$ etc). When seeds were kept under the total dark condition, they germinated on the pure agar or even in the sterilized distilled water. These indicate that neither extracts nor exudates from host plants are not necessary for germination. Further experiments were conducted to test the effect of various growth regulators (each 1$10 \mathrm{ppm}$ of IAA, NAA, 2-4-D, GA, kinetin and adenine), vitamins (each 1-50 ppm of vitamin $B_{1}, B_{2}, C$, biotin, Ca-panthotenate and nicotinic acid) and yeast extract on the germination, and it was showed that all of these substances did not stimulate the germination. However, the distinct effect of temperature and light on the germination was confirmed. Seeds did not germinate at all when they were kept under the continuous illumination with the diffused day light in the laboratory and with the artificial light at night for the first four days. When seeds were sown aseptically in the test tubes, incubated at $30^{\circ} \mathrm{C}$ for the first $4-15$ days and maintained subsequently at $25^{\circ} \mathrm{C}$ for 10-20 days, a better germination was observed.

The sown seeds kept in the dark at $30^{\circ} \mathrm{C}$ for the first seven days and subsequently at $25^{\circ} \mathrm{C}, 70-80 \%$ of germination was observed after 15-20 days. The optimum concentration of sucrose for the germination was from 0.5 to $1.0 \%$, but it was found to be tolerated between 0 and $7 \%$.

Root formation. A good root formation was obtained on the medium with ammonium salts as the nitrogen source, as in the case of our basic medium and Spoerl's medium. On White's or on B. K. P. medium, which does not contain any ammonium salt, rather the formation of callus tissue occurred. The germinating seedlings formed callus also by addition of various growth-regulators such as IAA, NAA, 2-4-D, GA, adenine, kinetin and yeast extract to the basic medium, but their color turned to dark brown and died within about two weeks.

The optimum concentration of sucrose for the root growth counted between 0.5 and $1.0 \%$. The seedlings grown on the basic medium with sucrose more than $5 \%$, turned to dark brown and died. The optimum temperature for the root growth was $20-25^{\circ} \mathrm{C}$. After 30-40 days stay under the optimum condition, the radicles of the germinating seedlings developed into roots. After 50 days, these seedlings which were forming root, were transplanted to the tubes con- 


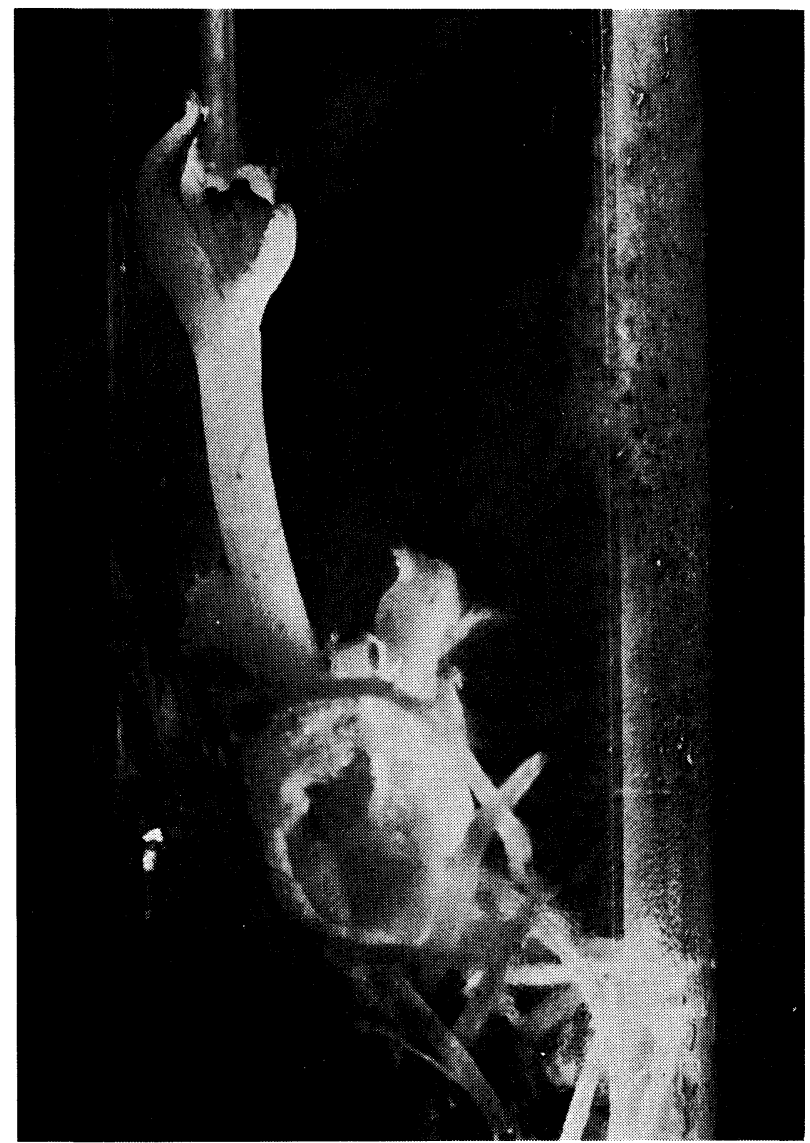

Fig. 1. The formation of the flower buds in 4 months-old Aeginetia plant cultured on the basic medium supplemented with watermelon juice.

taining fresh medium.

Shoot development. The normal and good shoot development were obtained on the basic medium. The subculture on the basic medium supplemented with watermelon juice up to 15 volume percent showed a better development than without the addition of juice. The optimum concentration of sucrose for the shoot growth was $2 \%$, in the culture at $25-30^{\circ} \mathrm{C}$ in the dark. The shoot began to develop well 80-90 days after sowing. As in the case of root formation, an addition of growth regulator made the seedlings brown and caused their death.

Flower initiation. Almost all plants which were acceptically subcultured on the basic medium with an addition of watermelon juice, flowered after four and a half to five months. The optimum condition for the initiation of flower primordia, was found in the 
culture containing $2 \%$ of sucrose, and kept in the dark at $15-25^{\circ} \mathrm{C}$. As shown in Fig. 1. from one to several normal flowers, which have four epipetalous anthers and an ovary containing many ovules were produced on each plant.

The results show that, throughout all development stages, this plant does not require any of the known growth regulators and extracts or exudates from the host roots for the seed germination and the flower initiation. For the germination, however, the temperature pretreatment at $30^{\circ} \mathrm{C}$ is favorable ${ }^{5}$ and the darkness is indispensable. ${ }^{9)}$ The better root and shoot formation were obtained when a medium containing ammonium salts was used and the plants were kept in the dark in addition. Clearly the supplement of watermelon juice promoted plant growth, ${ }^{9)}$ particularly that of shoot, and it accelerated the differentiation of the flower primordia. The optimum concentration of sucrose for the culture of the plant of present species was somewhat lower than that used in the case of the aseptic dark culture of other higher green plants (Pharbitis, ${ }^{15)}$ Raphanus, ${ }^{14)}$ Pisum, ${ }^{1)}$ Friticum, ${ }^{11)}$ Fagopyrum ${ }^{2)}$ etc.).

\section{References}

1) Haupt, W.: Zeitschr. Bot., 40, 1-32 (1952).

2) Inouye, J.: Plant \& Cell Physiol., 6, 167-177 (1965).

3) Kusano, S.: Bot. Mag. Tokyo, 17(195), 71-95 (1903).

$4)$ _ - Bull. College Agric. Tokyo Univ., VIII (1), 59-78 (1908).

5) Nakamura, S.: Mem. College Agric. Kyoto Univ. No. 86, 1-48 (1964).

6) Nygaard, P.: Physiol. Plant., 22, 338-346 (1969).

7) Okonkwo, S. M. C.: Amer. J. Bot., 53(7), 679-687 (1966).

8) — : Amer. J. Bot., 53(7), 687-693 (1966).

9) Ranga Swamy, N. S.: A symposium. Internat. Soc. Plant Morphol., Delhi, 345-354 (1963).

10) Spoerl, E.: Amer. J. Bot., 35, 38-95 (1948).

11) Sugino, M.: Bot. Mag. Tokyo, 70, 369-375 (1957).

12) Sunderland, N.: J. Exp. Bot., 11, 236-245 (1960).

13) — : J. Exp. Bot., 11, 356-366 (1960).

14) Tashima, Y.: Proc. Japan Acad., 29, 271-273 (1953).

15) Tashima, Y., and Imamura, S.: Proc. Japan Acad., 29, 581-585 (1953).

16) Tashima, Y. et al.: Mem. Fac. Agric. Kagoshima Univ., VIII, 121-125 (1972).

17) White, P. R.: A Handbook of Plant Tissue Culture. New York (1943). 